\title{
STUDENT - RELATED FACTOR FOR DROPPING OUT IN THE FIRST YEAR OF STUDIES AT LLU ENGINEERING PROGRAMMES
}

\author{
Anda Zeidmane, Tatjana Rubina \\ Latvia University of Agriculture \\ anda.zeidmane@1lu.lv, tatjana.rubina@1lu.lv
}

\begin{abstract}
In the 17th SEFI seminar, "Mathematical Education of Engineers", which was held in 2014, it was noted that many students have big problems starting their studies because of their lack of mathematical competencies. However, the low level of mathematical competence is not the only cause for dropping out in the first year of studies. There are many causes of student failure in universities and the main of them are: 1 ) studentrelated factors, 2) life and socioeconomic issues, 3) failures of the educational system. The aim of this research is to study the causes for dropping out in the first year of studies among engineering students at the Latvia University of Agriculture (LLU). The study is based on the analysis of mathematics test results of students from the Faculty of Engineering and the Faculty of Information Technologies as well as on the survey data analysis. The survey collected data and opinions regarding students': 1) attitude towards learning; 2) efforts in the study process 3) motivation and interest; 4) personality issues such as lack of social connections, lack of the support system and network, and poor self-esteem and self-confidence 5) economic issues. The analysis of the survey results showed that the core problem at the LLU is not only insufficient students' background knowledge in mathematics, but also their attitude towards learning, laziness to make efforts to do additional tasks or attend tutorials and lack of self-control. Students need to be motivated to want to learn and work hard to make faster gains and learn better than those who are bright but less motivated.
\end{abstract}

Keywords: causes of failures, student related factors, mathematics.

\section{Introduction}

Researches on student dropout causes [1-4] and possible prevention ranges take place from the early 20th century until now. Especially a large number of dropout students is in engineering specialities. In the 17th SEFI seminar, "Mathematical Education of Engineers", which was held in 2014, it was noted that many students have big problems starting their studies because of their lack of mathematical competencies. Similarly, at the Latvia University of Agriculture (LLU) more than $25 \%$ of the engineering specialities' students drop out just after the first year, in which mathematics is one of the basic subjects. Doing research on the reasons of failure in mathematics among engineering students at the Latvia University of Agriculture, which will be published in the International Scientific Conference REEP-2017, it was found that the low level of mathematical competence is not the only cause for dropping out in the first year of studies. Lot of the university teaching staff have surveyed their students to give their views on why students fail courses and drop out of college. As the root causes of the students' failure at the university motivation and study habits are mentioned. The other important factors mentioned are academic readiness and student attitudes. Of course, students, who have a good understanding of the content being taught, usually are more motivated and have more positive attitude, and thus have a greater chance of doing well in their schools. Students know that it is their responsibility to do well $[2 ; 4]$. At the same time, many students need extra support from their university.

The aim of the research is to investigate the reasons for the large number of dropout students in the engineering specialty during the first year. The study is based on the analysis of the teaching results as well as the survey data analysis. The survey collected data and opinions regarding the learners: their low basic knowledge, difficulties to understanding, learning habits, attitudes toward the learning process, motivation and social economic issues.

\section{Materials and methods}

As mentioned above, many universities are concerned about the large number of dropout students and many researches are devoted to the problem how to reduce the number of unsuccessful students. As recognized by many American professors, there is no better way to find out than to ask the students directly if something has helped and encouraged them to learn and succeed [1].

Motivation and study habits were mentioned most frequently as the root cause of student failure at the university level. Students in surveys often mentioned also academic readiness and student 
attitudes. These four factors are under the control of the students [2]. The students should be aware about the failing reasons of courses and they should take responsibility.

Motivation influences the students' attitudes, study habits, academic readiness, and so on. University administrators, faculty, educators, learning environment, instructional pedagogy and learning materials can help students succeed.

There are other factors that contribute for students failing courses at Kenya [3]:

- Student factors: entry behavior, motivation and attitude

- Socioeconomic factors: education of parents and their economic status

- School-based factor: availability and usage of teaching/learning facilities, school type and teacher characteristics.

The group of professors from the United States [4] did the research in the causes of student failure in universities, analyzing the problem and finding solutions that could productively lead to helping teaching staff teach and students learn and succeed. The research identified three main root-cause factors for students' failing: 1) student-related factors; 2) life and socioeconomic issues, 3) failures of the educational system (see Fig. 1).

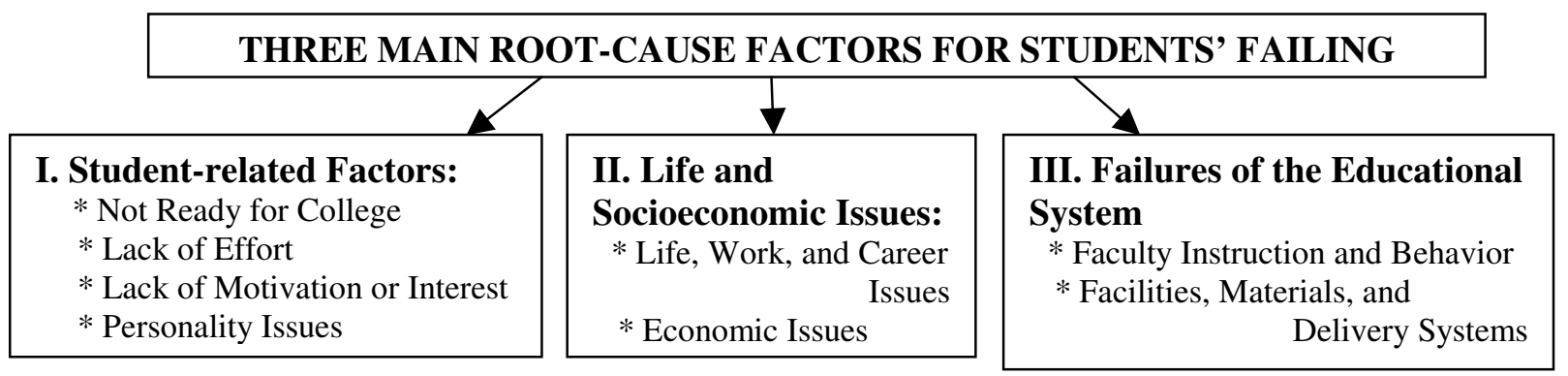

\section{Fig.1. Identified Categories of Root-Cause Factors [4]}

A significant number of incoming students is not ready for university-level work. They have the lack of background knowledge in core subjects, especially mathematics and physics, the lack of learning and study skills as well as the lack of organizational skills (including time management and setting priorities).

In order to determine the background knowledge in mathematics and increase the opportunities to study engineering with low basic knowledge in mathematics, in the Department of Mathematics of the Latvia University of Agriculture (LLU), firstly, the test was organized on the elementary questions in mathematics, and secondly, as one of the possibilities to improve the basic knowledge in mathematics, free mathematical remedial courses were offered to the students. Unfortunately, the students' interest in these courses was very small [5]. It really shows the LLU students' low organizational skills, especially setting priorities.

Many students have an inability to think critically, an inability to express oneself in a written format, and an inability to comprehend the nature of assignments.

The lack of effort and poor or non-existent work ethics are no less important factors. Many students are unaware of the problem, if she/he lacks prior knowledge and learning skills in any subject, then, learning this subject requires more effort. Relatively often students do not complete assignments and consider that homework is unimportant. Similarly, Professor Ibrahim [6] from Nigeria in his research recognized that failure in mathematics was due to apathy or hatred for the subject, laziness or lazy attitude to studying the subject. With regard to the ethics of learning, many students sometimes do not seek to focus on the learning process and devote insufficient attention during classes. In addition, sometimes students come to the class late or do not attend classes, sometimes they send texts or play video lessons or otherwise do not pay attention. Students do not read the material before the class and do not complete their tasks. There are even students who do not value education because they do not have to work to pay for it or, if they fail, they can always repeat the course. 
Lack of motivation or interest, persistence, and "not being active learners" are important categories, too. Some students even do not care if they are students at a university or not. In the Latvian University of Agriculture, the largest number of dropouts is in the first course. Carrying out a survey among the first-year students, the fact surprised that many students had chosen the specialty at the last moment and knew very little about the chosen profession. Some failing students have little understanding of how their education relates to their lives. They do not know what they want in life and do not have clear goals. Some have no idea where they are going. Perhaps, the family or friends are putting pressure on the students - they are not motivated to do the work and either do not want to be in the university.

The factor of personality issues should not be overlooked comprising the lack of social connection, lack of support system and network and poor self-esteem and self-confidence. The general feeling is that if students were "active on campus, and have interactions with the faculty and students outside the classroom," they would be more likely to succeed in university. Very important is the atmosphere in student groups. If most of the students have completed their homework and got good results on tests, then the others will make more efforts so as not inferior others. If most of the groups are not motivated to be good at learning, then the others carried out only the minimum necessary to pass the test. In addition, it is essential for the common activities - both the Faculty days Specialties day and sports competitions, etc.

The factors "Life and Socioeconomic Issues" and "Failures of the Educational System" that affect students' academic failure are important, too, but solution of these problems requires changes in the study program and in all educational system, and it is not the responsibility of the authors.

In order to achieve the aim of the research, the survey was carried out. The survey questions were divided into the following four groups: 1) students' success measured by grades, 2) work invested in the learning process, 3) attitude to the learning process, 4) students' activities outside the study process, 5) students' social conditions.

The following research methods were used to analyse the survey results: descriptive statistics and correlation analysis.

\section{Results and discussion}

The existence of a good knowledge in mathematics provides the student with greater opportunities to study engineering successfully. The research was performed in the Department of Mathematics of the Latvia University of Agriculture with the aim to investigate the reasons for the large number of dropout students in the engineering speciality in the first year. In the research the students' results and survey data from two engineering faculties were processed: 1) Faculty of Information Technologies (FIT) and 2) Engineering faculty (EF). In order to determine the level of student's basic knowledge in mathematics, the test was organized on the elementary mathematical concepts. In total, the test included $721^{\text {st }}$ year students from FIT and 64 students form EF. Test results on the elementary concepts of the students from the FIT and EF are shown in Fig. 2.

a)

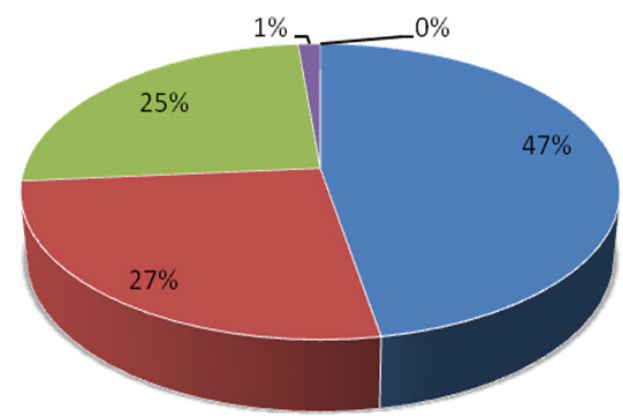

b)



Fig. 2. Students' tests results on the elementary mathematical concepts: a - students from the Faculty of Information Technology; b - students from the Engineering Faculty

The results obtained in 2015 [5] showed that only $24.7 \%$ of the first year students from FIT have received more than $70 \%$ of the assessment score and more than $45 \%$ of students have received less than $50 \%$ of the score. Comparing this year test results with 2015, it can be concluded that students' 
knowledge in mathematics had become even worse. This year, only one student from FIT has received more than $70 \%$ of the assessment score. He obtained 73 points out of 100 possible. More than $73 \%$ of students have received less than $50 \%$ of the score. A similar situation is observed at the EF. No students from EF received more than $70 \%$ and more than $87 \%$ of the first year students received less than $50 \%$ of the score.

As all students on completion of secondary schools had to take the centralized examination in mathematics, the correlation was made between the results of the LLU test on elementary mathematical concepts, centralized secondary school exam score and the final grade of the LLU course test in mathematics. The strength of the correlation was characterized using the guide that Evans [7] suggests for the absolute value of $r$. In case of FIT students there was a positive weak correlation determined between the final core of the LLU test and the grade in the LLU test on elementary mathematical concepts $r_{S}=0.33(p=0.01)$. In case of $\mathrm{EF}$, the correlation results are similar. There was positive weak correlation found between the test final grade in mathematics in LLU, the results of the LLU test on elementary mathematical concepts $r_{S}=0.36(p=0.01)$ and the grade in the centralized secondary school exam in mathematics $r_{s}=0.37(p=0.01)$.

To determine the influence of the basic knowledge level in mathematics and other factors on the course test final grade, the analysis was performed. The course test results, i.e. students' distribution by the final grade, are shown in Figure 3.

a)

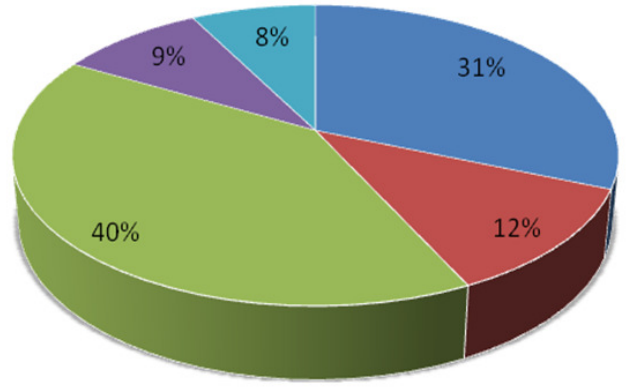

b)



Fig. 3. Students' course test results in mathematics: a - students from the Faculty of Information Technology; b - students from the Engineering Faculty.

Summarizing the results of 77 students from FIT, $69 \%$ of the students have successfully acquired the course test. Pleased that despite the weak basic knowledge in mathematical concepts $17 \%$ of the FIT students received 7 and more points of the score. The results show that $31 \%$ of the interviewed students have not completed the course. It should be noted that $15 \%$ of them did not take part at all in the learning process, as well as $71 \%$ of the interviewed students (17 students from 24$)$ received less than $50 \%$ of the score in the LLU test on the elementary mathematical concepts. Interesting is the fact, that $88 \%$ of the students that have not completed the course successfully, have not done homework at all or have executed part of the assigned homework and $8 \%$ failed to comply it in a timely manner. Hope-providing fact is that none of the students from FIT, who executed homework in time, have dropped out and the average grade of this group part is 6.5 points (all group average grade $-5.8)$.

The course test results of the EF students are similar. From 66 interviewed students $74 \%$ of students have acquired the course test successfully. Also students from EF have got good grades completing the course. $11 \%$ of the interviewed students received 7 and more points of the score. $35 \%$ of the dropped out students did not take part at all in the learning process. $94 \%$ dropped out students (15 students from 16) received less than $50 \%$ of the score in the LLU test on the elementary mathematical concepts. Similar to the FIT students, none ofthe students from EF dropped out who executed homework in time and the average grade of this students' part is 5.4 points (all group average grade -5.2). But $50 \%$ of unsuccessful students in the LLU mathematics course have executed part of the assigned homework or failed to comply it in a timely manner.

The correlation was made between the timely done homework and the final grade of the course test in mathematics. In case of FIT, there was a positive weak correlation determined $r_{S}=0.32$ $(p=0.05)$. But in the case of the EF students there was a positive moderate correlation determined $r_{S}=0.52(p=0.05)$. 
During the survey data on students' competencies were collected with the aim to determine the course test grade correlation with the acquired competencies. There was a positive weak correlation determined between the final core of the LLU course test and math thinking competence: FIT students' $r_{S}=0.41(p=0.01)$ and $r_{S}=0.30(p=0.05)$ for students from EF. In the case of the EF students, there was a positive weak correlation found between the final core of the LLU course test, problem solving $r_{S}=0.32(p=0.05)$ and opinion formation $r_{S}=0.43(p=0.01)$ also.

a)

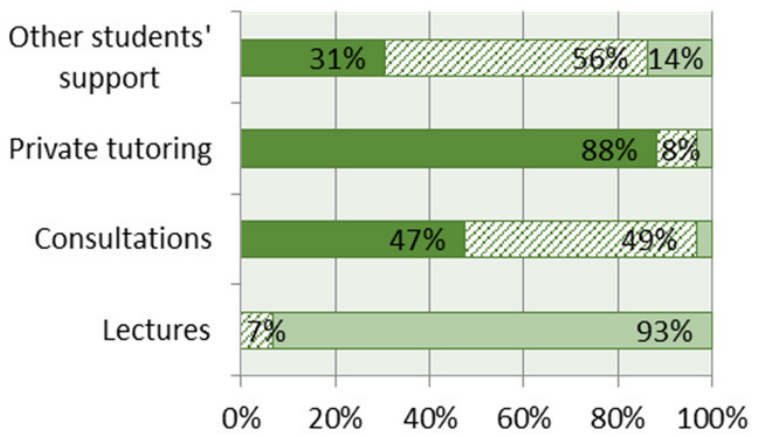

b)

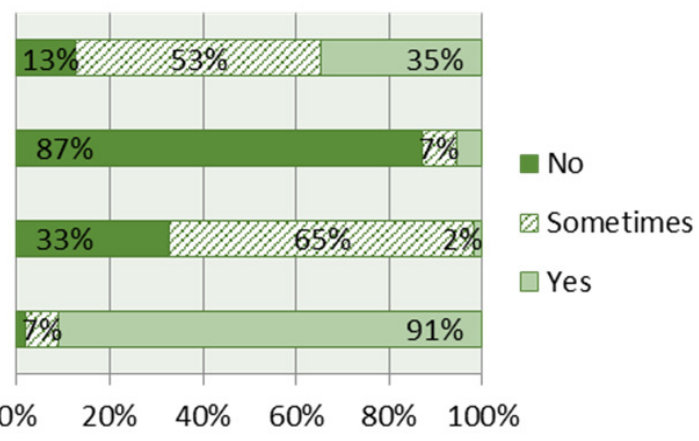

Fig. 4. Students' opinion regarding factors helping to improve their mathematical knowledge: $\mathrm{a}$ - students from the Faculty of Information Technology; $\mathrm{b}$ - students from the Engineering Faculty

To improve the basic knowledge and consolidate the newly acquired knowledge in mathematics many possibilities were offered to the students: to attend free mathematical remedial courses, to use designed summary and to attend the consultation. Students are able to use private tutoring and an opportunity to use better students' support also. Unfortunately, the students' interest in remedial courses was very low. Such a trend has been observed for three consecutive years. Every year less that indicates the lack of motivation and diligence to improve their knowledge in mathematics. Students have the opportunity to attend the consultation, during which not only the current matter was provided, but also advice on the basic concepts in mathematics. From all offered opportunities $2 \%$ of students from EF attend consultations regularly and $4 \%$ of FIT students. $65 \%$ of students from EF and $49 \%$ from FIT attend sometimes (mode $=$ median $="$ Sometimes"). Only $5 \%$ of the students from EF use private tutoring (mode $=$ median $="$ No") and more likely prefer to turn to colleagues for help (mode $=$ median $=$ "Sometimes"). $35 \%$ of the EF students use better students" support regularly and more than $50 \%$ of both faculties' students turn for help sometimes (see Fig. 4).

Gratifies the fact that students are keen to attend lectures (mode = median = "Yes"): $93 \%$ of the students from FIT and $91 \%$ of the students from EF attend more than $70 \%$ of lectures.

One of the most important factors that influence the students' results is motivation to study the chosen speciality. To find out the reasons for studying the chosen speciality the survey was carried out. Students were offered thirteen factors. From the offered factors most students from both faculties chose the desire to get higher education (71\% from FIT and $85 \%$ from EF), interest in the profession ( $68 \%$ from FIT and $62 \%$ from EF), the desire to become competent professionals (53\% from FIT and $80 \%$ from EF) and increase of career opportunities (58\% from FIT and $58 \%$ from EF). These factors can be called primary motivation factors. As secondary motivation factors approximately $17 \%$ of the FIT students have chosen parents' recommendation, university located closer to the dwelling place and accession with friends. While the students from FIT make their choice based on the recommendations and location, for the $\mathrm{EF}$ students the determining factor is the cost. As secondary motivation factors the EF students named opportunity to study on a budget ( $29 \%$ of the students from EF, $10 \%$ from FIT), less costly daily life than in Riga ( $22 \%$ from EF, $10 \%$ from FIT) and the university location closer to the dwelling place (20\% from EF) (see Fig. 5).

No less important is the role of social factors and employment. Certainly working students have less time for studies than unemployed (see Fig. 6). For this reason, during this research social factors were analysed. Analysis of the results shows that both faculties' students do not have enough social life. $88 \%$ of the students from FIT and $84 \%$ from EF rarely visit clubs. $79 \%$ of the students from FIT and $73 \%$ from EF rarely visit cultural events. $88 \%$ from the FIT students do not participate in community work and $86 \%$ from EF, as well as they do not operate in any cooperation: $92 \%$ of the students from FIT and $84 \%$ of the EF students. 
university located closer to dwelling place

less costly daily life than in Riga

come together with friends opportunity to study on a budget

parents suggested

opportunity to start working later

opportunity to be in society of educated people

increase career opportunities

are good at exact sciences

specific object exploration

interest in the profession

desire to get higher education

desire to become competent professionals
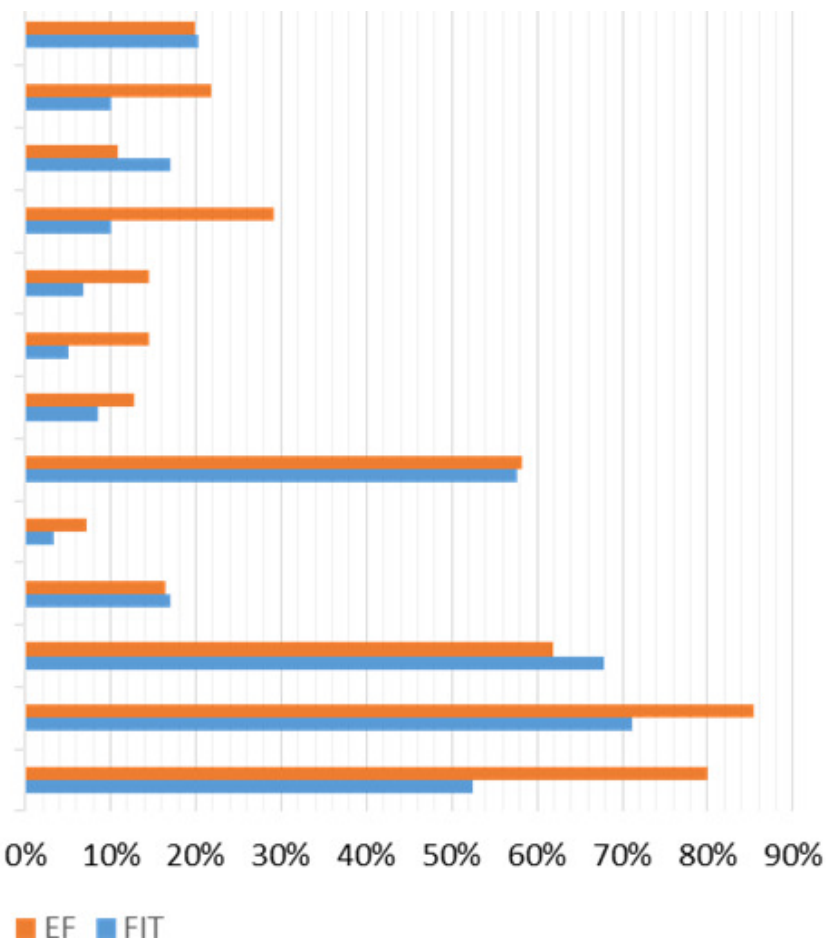

Fig. 5. Students' opinion regarding motivation factors

a)

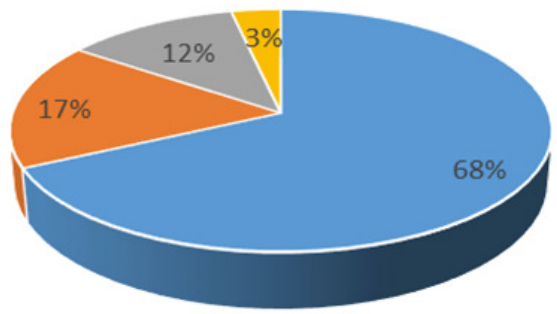

b)

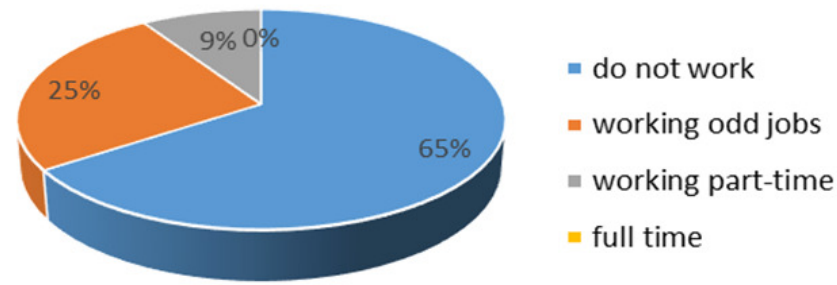

Fig. 6. Students' employment: a - students from the Faculty of Information Technology; $\mathrm{b}$ - students from the Engineering Faculty

The performed correlation analysis showed that in the case of the FIT students there is only negative weak correlation between the LLU course test and club visiting $r_{s}=-0.41(p=0.01)$. But the students' data analysis from the EF showed only statistically insignificant positive weak correlation between the course test and operation in cooperation $r_{s}=0.263$ and living place (see Fig. 7) $r_{s}=0.246$.

a)

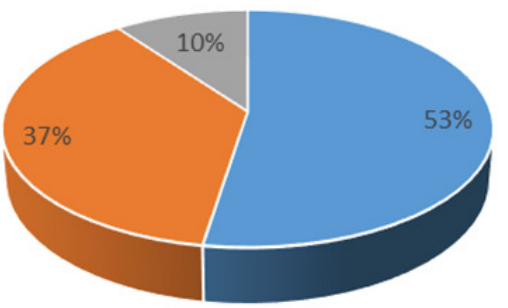

b)

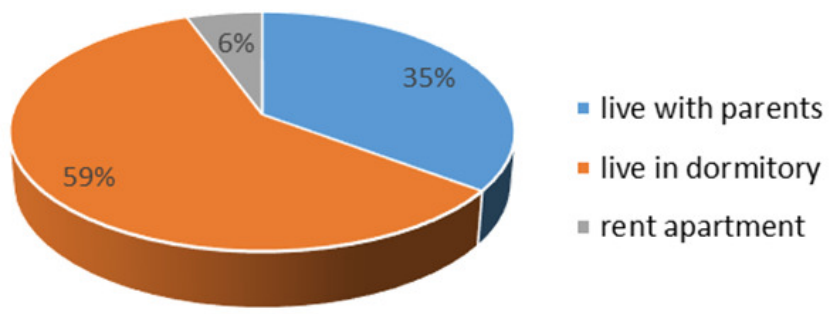

Fig. 7. Students' living place: a - students from the Faculty of Information Technology; $\mathrm{b}$ - students from the Engineering Faculty

\section{Conclusions}

1. The results analysing the first year students in 2017 show mostly average basic knowledge of mathematical concepts. The results of the students from FIT are slightly better than the FE students' results. But unfortunately, generally the students' knowledge in the mathematics basic concepts every year gets worse. Students with poor background knowledge in mathematics provide extra work for the teaching staff. 
2. For the LLU students different possibilities are offered to improve their knowledge of mathematics, but many students do not use them. It shows that the main root-cause factor for students' failing is student-related factors.

3. Students are not ready for university-level work. They have the lack of background knowledge, the lack of learning and study skills as well as the lack of organizational skills. Students show laziness against the learning process and are not accustomed to independent work. As evidenced by the survey results, only few students attend the offered free mathematical remedial courses and during the semester only $2 \%$ of the students from EF attend consultations regularly, and $4 \%$ of the FIT students. Timely completed homework provides the basis for successful learning. This fact indicates results of both analyzed groups. All the students who did homework on time have successfully passed the course test.

4. One of the important factors that influence the students' results is motivation to study the chosen specialty. Approximately $17 \%$ of the FIT students have chosen it due to parents' recommendation, the university located closer to the dwelling place and accession with friends. Many students as motivation factors named opportunity to study on a budget ( $29 \%$ of the students from EF, $10 \%$ from FIT).

5. The research has shown that the social factors and employment are not so important; because students are not active (88 \% of the students from FIT and $84 \%$ from EF rarely visit clubs. $79 \%$ of the students from FIT and $73 \%$ from EF rarely visit cultural events). Only on average $10 \%$ of the students from both faculties work pat-time.

6. The general feeling is that if students were active on campus and have interactions with the faculty and students outside the classroom, they would be more likely to succeed in university. The atmosphere in student groups is very important.

\section{References}

1. Bain K. What the best college teachers do. Cambridge, MA, Harvard University Press: 2004. $203 \mathrm{p}$.

2. Cherif A., Movahedzadeh F., Adams G. etc. Why do students fail? In a collection of papers on self-study and institutional improvement, Chicago: 2013, pp. 35-51.

3. Mbugua Z., Kibet K., Muthaa G. etc. Factors Contributing To Students' Poor Performance in Mathematics at Kenya Certificate of Secondary Education in Kenya: A Case of Baringo County, Kenya. American International Journal of Contemporary Research, Vol. 2, No. 6; June, 2012. pp. 87-91. [online] [24.09.2016]. Available at:

http://connection.ebscohost.com/c/articles/72885906/factors-contributing-poor-performance-

kenya-certificate-primary-education-public-day-primary-schools-mwimbi-division-maara-districtkenya

4. Cherif A., Adams G., Movahedzadeh F. etc. Why Do Students Fail? Faculty's Perspective. Annual conference. Creating \& Supporting Learning Environments, 2014 [online] [10.10.2016]. Available at: http://cop.hlcommission.org/Learning-Environments/cherif.html

5. Zeidmane A, Korolova J. Opportunities of Studying Engineering in Latvia University of Agriculture with Low Basic Knowledge in Mathematics. Proceedings of the $8^{\text {th }}$ International Scientific Conference "Rural Environment. Education. Personality. (REEP)", May 24-27, 2015, Jelgava, Latvia, pp. 407-413.

6. Ibrahim M. Why students fail Mathematics. [online] [30.09.2016]. Available at: http://www.vanguardngr.com/ 2015/04/why-students-fail-mathematics/

7. Evans J. Straightforward statistics for the behavioral sciences. Pacific Grove, CA: Brooks/Cole Publishing, 1996, $600 \mathrm{p}$. 